\title{
Differences in educational attainment between obese and non-obese Kuwaiti female university students
}

\author{
Hanouf H. Al Hammadi ${ }^{1}$, Hamad A. Alaslawi ${ }^{2}$, Allan Hewitt ${ }^{1}$ and John J. Reilly ${ }^{1} *$ (] \\ ${ }^{1}$ School of Psychological Sciences and Health, University of Strathclyde, Glasgow G1 1XQ, UK \\ ${ }^{2}$ Department of Sociology and Social Work, College of Social Sciences, Kuwait University, Kuwait
}

(Received 2 February 2020 - Final revision received 23 June 2020 - Accepted 26 June 2020)

Journal of Nutritional Science (2020), vol. 9, e30, page 1 of 5

doi:10.1017/jns.2020.24

Abstract

Individuals with obesity tend to perform less well than their non-obese peers in tertiary education, but there is little evidence from non-Western countries and recent studies. The present study aimed to test whether academic attainment differed between female undergraduates with obesity (defined by body mass index (BMI)), and those who were non-obese in Kuwait, a country with very high obesity prevalence. In 400 female Kuwaiti first- and second-year Social Science students (mean age 18.0, sD $0 \cdot 6$ years), educational attainment was defined as the Grade Point Average (GPA) across all subjects (from $1 \cdot 00$ to $4 \cdot 00)$. The mean GPA $(2 \cdot 51$, sD $0 \cdot 53)$ among students defined as obese by the BMI $(n 163)$ was significantly lower than among the students defined as non-obese by the BMI $(n 237 ; 2 \cdot 80$, SD $0.63 ; P<0.001)$, and those defined as obese were more likely to be in the lowest quartile for the GPA (OR 3.03; $95 \%$ CI 1.90, 4.85), independent of socio-economic status. Similar differences were observed between students defined as having high versus normal body fatness. Female undergraduates in Kuwait with obesity have lower academic attainment than their non-obese peers, and universities should consider measures to mitigate reduced attainment among their female undergraduates.

Key words: Obesity: Adolescents: Body mass index: Kuwait: Academic achievement

In Kuwait, more than $40 \%$ of adults have obesity as defined by the $\mathrm{BMI}^{(1-5)}$. The prevalence of obesity is also extremely high among Kuwaiti children and adolescents ${ }^{(6,7)}$. Obesity rates are still rising among Kuwaiti adults and children, costing the country a minimum of $2 \cdot 8$ billion dollars annually in both direct and indirect $\operatorname{costs}^{(8)}$; with a Kuwaiti population of only $1 \cdot 1$ million, ${ }^{(9)}$ Kuwait has about 5000 bariatric procedures each year ${ }^{(10)}$.

Obesity in childhood, adolescence and adulthood increases the risk of a large number of medical problems ${ }^{(11-13)}$. If obesity impairs educational attainment, this could provide new arguments for obesity prevention and treatment ${ }^{(14-17)}$. In the $\mathrm{UK}$, for example, a large cohort study by Booth et al. ${ }^{(14)}$ found that obesity in adolescence was associated with markedly poorer academic attainment, independent of confounders, but in girls only. Recent systematic reviews have disagreed on the quality, quantity and consistency of the evidence on differences in academic attainment between individuals with obesity and those who do not have obesity: Santana et al. concluded that deficits in academic attainment in individuals with obesity might be explained largely by confounding (with obesity much more prevalent in individuals with lower socio-economic status in high-income Western countries) and called for more research on the issue ${ }^{(15)}$. Hill et al. ${ }^{(16)}$ concluded that deficits in academic attainment in undergraduates with obesity were fairly well established, particularly in women, and might be explained largely by weight-related bias. The Cochrane review by Martin et al. ${ }^{(17)}$ highlighted plausible mechanisms relating obesity to lower academic attainment including social mechanisms such as stigma/bias and impaired quality of life associated with obesity, biological mechanisms (such as cognitive

Abbreviations: BMI: body mass index: GPA: Grade Point Average

* Corresponding author: John Reilly, e-mail john.j.reilly@strath.ac.uk

(C) The Author(s), 2020. Published by Cambridge University Press on behalf of The Nutrition Society. This is an Open Access article, distributed under the terms of the Creative Commons Attribution licence (http://creativecommons.org/licenses/by/4.0/), which permits unrestricted re-use, distribution, and reproduction in any medium, provided the original work is properly cited. 
effects of inflammation $)^{(18,19)}$ and mechanisms related to poor health associated with obesity (such as illness-related absenteeism). An additional systematic review ${ }^{(20)}$ concluded that impaired academic attainment associated with obesity was most likely in adolescent girls and young adult women ${ }^{(20)}$.

Since systematic reviews on the topic have not reached consistent conclusions, other than the likelihood that obesity-related deficits in attainment may be worse in females than males, and almost all research included in those reviews comes from older studies in high-income Western nations, there is a need for new research from a wider range of settings. The primary aim of the present study was therefore to test whether educational attainment in Kuwaiti undergraduates was lower in individuals with obesity. We studied female undergraduates because of the previous evidence that obesity-related deficits in attainment might be worse in females than males.

\section{Methods}

The present study recruited a convenience sample of first- and second-year Kuwaiti University College of Social Science students between March and May 2019. Sampling and recruitment have been described in detail elsewhere ${ }^{(21)}$. In brief, all first- and second-year Social Science undergraduates were invited to take part by the researcher. Students were considered suitable for inclusion if they were female, Kuwaiti nationals, $<20 \cdot 0$ years of age and did not have any condition or illness which would have altered their weight status (e.g. pregnancy and long bone fracture). Students were excluded if they were male, non-Kuwaiti nationals, $20 \cdot 0$ years or older and had any condition or illness affecting their weight status, or reported any other chronic disease. The aim of these inclusion and exclusion criteria was to provide a relatively homogenous sample, and one which was relatively free of a number of potential confounders (e.g. non-Kuwaiti nationality and age). Of the 2169 students contacted, 525 expressed an interest and 400 of these were eligible and were entered into the study. All participants gave informed written consent to participation, and the study was approved by the University of Strathclyde Psychological and Health Sciences Ethics Committee.

\section{Measures of exposure (BMI and body fatness)}

Anthropometric measurements and BMI calculations were carried out as described by Al-Hammadi and Reilly ${ }^{(21)}$. A Seca Stadiometer (Seca, London, UK) was used to measure the height to the nearest $0 \cdot 1 \mathrm{~cm}$. Weight was measured to $0 \cdot 1 \mathrm{~kg}$ with study participants in light indoor clothing by the Tanita model TBF-310 (2625 South Clearbrook Drive Arlington Heights, IL, USA). A BMI $z$-score of $\geq 2 \cdot 0$ relative to $\mathrm{WHO} 2007^{(22)}$ reference data was used to define obesity in the adolescents (17-19.0) years of age ( $n$ 275) and for those over $19 \cdot 0$ years old the adult cut-off point of BMI $\geq 30 \mathrm{~kg} \mathrm{~m}^{2}$ was used $(n 125)^{(23)}$.

\section{Educational attainment measurement}

The measure of educational attainment outcome used in the present study was the Grade Point Average (GPA) for all university subjects. The GPA was provided in an anonymised form from the university authorities. The GPA was used in two ways: as a continuous variable (from 1.00 to 4.00 ) and a categorical variable, with the GPA distribution divided into quartiles from highest (Q1) to lowest (Q4).

\section{Potential confounders}

In high-income Western countries, socio-economic status is a potential confounder of obesity-educational attainment relationships because it is associated with both higher risk of obesity and lower educational attainment ${ }^{(15,20)}$. Socio-economic status was considered as a potential confounder in the present study using parental educational attainment (degree education versus education to the high school level). Despite the relatively narrow age range, we also considered student age as a potential confounder.

\section{Statistical analysis}

Data were analysed with SPSS version 26 (IBM Corp., Armonk, NY, USA) and Medcalc (Belgium). The data were tested for normality, and summary data were described as mean (standard deviation (SD)) or median (range) depending on the distribution of variables which was assessed by plots of the data and D'Agostino-Pearson tests in MedCalc. We compared the GPA between students categorised as obese by the BMI versus those considered non-obese by the BMI using two-sample $t$-tests. We also compared the percentage with obesity among the GPA quartiles using both $\chi^{2}$ tests and calculated odds ratios for risk of being in the lowest GPA quartile by obesity. $P$-values of $<0 \cdot 05$ were used to indicate statistical significance.

The power of the present study was difficult to assess at the outset, and the power was fixed as this was part of a wider study of the ability of BMI to identify excessive fatness among female Kuwaiti adolescents ${ }^{(21)}$.

\section{Results}

\section{Characteristics of study participants}

A total of 525 students agreed to take part in the study, and 125 were excluded as they did not meet the inclusion criteria (age over $20 \cdot 0$ years, pregnancy, long bone fracture in cast and presence of chronic diseases). Therefore, 400 actually took part, and all 400 provided data for all variables. Of 400 participants, 163 were defined as obese based on the BMI and 247 were defined as excessively fat based on the bio-impedance measure.

\section{Educational attainment differences between individuals with obesity and those who did not have obesity}

The mean GPA in the overall sample of 400 was 2.68 (SD $0 \cdot 62)$. The mean GPA in the sample with obesity defined by the BMI ( $n$ 163) was 2.51 (SD 0.53; 95\% CI 2.42-2.59), and the mean GPA in participants defined as not having obesity according to their BMI (n 237) was 2.80 (SD 0.65; 95\% CI 
Table 1. Grade point average (GPA) quartiles by weight status

\begin{tabular}{|c|c|c|c|c|}
\hline & $\begin{array}{l}\text { Quartile } 1 \\
\text { Highest }\end{array}$ & Quartile 2 & Quartile 3 & $\begin{array}{l}\text { Quartile } 4 \\
\text { Lowest }\end{array}$ \\
\hline GPA range & $4.00-3.00$ & $3 \cdot 00-2 \cdot 70$ & $2 \cdot 70-2 \cdot 10$ & $2 \cdot 10-1.00$ \\
\hline Mean GPA (SD) & $3.44(0.32)$ & $2.92(0.11)$ & $2.48(0.16)$ & $1.88(0.27)$ \\
\hline $\begin{array}{l}\text { Obese by the } \\
\text { BMIn } 163\end{array}$ & 28 & 35 & 39 & 61 \\
\hline Non-obesen 237 & 72 & 65 & 61 & 39 \\
\hline
\end{tabular}

$2 \cdot 71,2 \cdot 88)$. This difference was statistically significant $(P<$ $0 \cdot 001 ; 95 \% \mathrm{CI}$ for difference in means $=0 \cdot 17,0 \cdot 41$ ).

A $\chi^{2}$ test on the distribution of GPA quartiles by obesity versus non-obesity status using the BMI was statistically significant $(P<0.001$; Table 1). The odds ratio, unadjusted, for risk of being in the lowest quartile of GPA in the individuals with obesity according to the BMI was 3.03 (95\% CI 1.90 , $4.85 ; P<0 \cdot 001)$. Student age and parental educational attainment were not associated with the exposure and outcome values, and did not confound the relationship between BMI-defined obesity and the GPA.

\section{Discussion \\ Main findings and study implications}

The present study found that undergraduates with BMI-defined obesity had poorer overall academic attainment than those who did not have obesity, and this difference could not be explained by socio-economic status. The impact of obesity on educational attainment might be helpful in both obesity prevention and treatment ${ }^{(14)}$. Individuals and families may be motivated to change weight status or health behaviours for cognitive or educational benefits. The very high prevalence of obesity in Kuwait, combined with the importance of educational attainment, might therefore provide new/additional arguments for obesity prevention and treatment in Kuwait and the other Gulf States. Universities should also be more aware of the increased risk of poorer attainment among undergraduates with obesity and have a particular responsibility to do so if at least some of this poorer attainment relates to bias or stigmatisation from peers and/or university staff ${ }^{(16)}$. The magnitude of the difference in the GPA between groups in the present study might also be sufficient to motivate universities to address the issue in future, even if only to raise student attainment.

\section{Comparisons with other studies}

Recent systematic reviews ${ }^{(15-17,20)}$ have generally concluded that obesity pre-disposes to lower academic attainment, particularly in girls and women. However, some of these reviews have questioned whether this might be explained by confounding by socio-economic status, with poverty being associated with both lower academic attainment and obesity in high-income Western countries. Systematic reviews and original studies have identified a number of plausible mechanisms by which obesity might impair educational attainment.
Potential mechanisms ${ }^{(15-17,20,24-27)}$ include increased absenteeism from university or school associated with the co-morbidities of obesity; cognitive deficits associated with cardiometabolic co-morbidities; impaired quality of life and the psychosocial co-morbidities of obesity; the impact of obesity on brain structure and/or function particularly in the prefrontal cortex and hippocampus; the impact of obesity on behaviours known to be associated with educational attainment such as reduced moderate-vigorous intensity physical activity or less healthy diet and weight stigmatisation by peers or teachers. The present study was designed to test whether academic attainment was lower in female undergraduates with obesity and was not designed to identify mechanisms underlying this difference. However, some cultural and socio-economic differences between Kuwait and high-income Western countries might help in the development of future research aimed at understanding why the differences observed in the present study exist. First, poverty is almost non-existent among Kuwaiti nationals, and income inequality is extremely low in Kuwait compared with high-income Western countries ${ }^{(28,29)}$. There is also some evidence that obesity is not confounded by socio-economic status in Kuwait, in contrast to Western countries ${ }^{(30)}$. Weight stigmatisation and psychosocial impacts of obesity among adolescent girls and adult women may also differ between Kuwait and other nations. There is limited evidence on such differences to date, but impaired quality of life is the norm among adolescents with obesity in Western countries, but not present in Kuwaiti adolescents ${ }^{(31)}$.

\section{Study strengths and weaknesses}

The present study had a number of strengths. First, the focus on adolescent girls and women, the groups most likely to experience obesity-related impairment of educational attainment, was important. Second, the novelty of the study was high because of the non-Western setting and the contemporary sample (with most of the previous literature from undergraduates from an era when obesity prevalence and access to tertiary education were very different $\left.{ }^{(16)}\right)$. Third, we examined potential confounding by socio-economic status, considered crucial by a number of previous reviews, notably Santana $e t$ al. ${ }^{(15)}$

The present study used the BMI to define obesity (obesity is a high level of body fatness rather than a high BMI ${ }^{(21)}-$ while the BMI is a convenient proxy for high body fatness, it has only moderate sensitivity for high body fatness in Kuwait and in other populations ${ }^{(21)}$. In an attempt to address this potential weakness, we also tested for differences in academic attainment between individuals defined as having high body fatness ( $\geq 30 \%$ of body weight, as estimated by bio-electrical impedance) versus those with lower body fatness in the present study. This analysis is summarised in Supplementary Table S1 of Supplementary material, but results and conclusions were very similar to those from the analysis based on BMI-defined obesity. The power of the study was difficult to assess at the outset, but the sample size was sufficient to detect significant associations. The present study sample of 400 undergraduates was derived from a potentially eligible population of about 1800 , and the extent to which biases in 
recruitment to the study affected study findings are unclear. Defining socio-economic status by income is problematic in Kuwait with such limited variation in income relative to Western countries ${ }^{(28-30)}$ - the present study used parental educational attainment as a convenient and relevant individuallevel indicator of socio-economic status, but there is probably no ideal single measure. The present study was not designed to identify the mechanisms of any associations, and further studies will be required to do so. The generalisability of the findings is also unclear and will need to be tested in other studies. Finally, the present study had a cross-sectional design and so is restricted to identifying differences in academic attainment between individuals with obesity versus those who did not have obesity, and cannot confirm that obesity is a cause of lower academic attainment. However, the present study findings were consistent with a good deal of other evidence, there are plausible biological and social causal mechanisms, and reverse causality (lower educational attainment causing obesity and excessive fatness) is possibly unlikely in this case.

Conclusions. This research suggests that having obesity may impair academic attainment in Kuwaiti female students. Further studies will be needed to test the generalisability of these findings and to identify the underlying mechanisms of any effect of obesity on educational attainment.

\section{Supplementary material}

The supplementary material for this article can be found at https://doi.org/10.1017/jns.2020.24.

\section{Acknowledgments}

The authors acknowledge the practical support of the Dean of Social Science at Kuwait University, Aisha Almotari, Dana AlKandari and all Social Science Faculty and staff. The authors are also grateful to Shaima Alqattan from Adan Hospital and the Kuwait Institute for Scientific Research (Mr Hasan AlAttar and his colleagues, and to Dr Manal Eshelli) also to all the student participants.

The work was funded by the Public Authority for Applied Education and Training Institute, Kuwait.

J.J.R. and A.H. were responsible for the initial concept of the study. All authors refined and finalised the study concept, and designed the study. All authors were responsible for the choice of methods and analyses, and all authors were involved in data analysis and interpretation. H.A. collected the data. H. A. did the initial draft of the manuscript, all authors revised the manuscript for critical content, and all authors approved the final manuscript and the decision to submit.

The authors have no conflicts of interest to declare.

\section{References}

1. Rotimi K (2005) Kuwait has the highest obesity level in the world: a policy proposal to reduce prevalence. 133rd Annual Meeting \& Exposition, December 10-14. Philadelphia, PA: American Public
Health Association. https://apha.confex.com/apha/133am/techprogram/paper_110761.htm.

2. Hashem R, Rey-Lopez JP, Hamer M, et al. (2019) Associations between objectively assessed and questionnaire-based sedentary behaviour with body mass index and systolic blood pressure in Kuwaiti adolescents. BMC Res Notes 12, 1-6.

3. Nahhas MA, Asamoah F, Mullen S, et al. (2018) Epidemiology of overweight and obesity in early childhood in the Gulf Cooperation Council countries: a systematic review and meta-analysis protocol. BMJ Open 8, e019363.

4. $\mathrm{Ng} \mathrm{M}$, Fleming T, Robinson M, et al. (2014) Global, regional, and national prevalence of overweight and obesity in children and adults during 1980-2013: a systematic analysis for the Global Burden of Disease Study 2013. Lancet 384, 766-781.

5. Weiderpass E, Botten E, Longenecker JC, et al. (2019) The prevalence of overweight and obesity in an adult Kuwaiti population in 2014. Front Endocrinol 10, 449.

6. Al Hammadi H \& Reilly J (2019) Prevalence of obesity among school-age children and adolescents in the Gulf cooperation council (GCC) states: a systematic review. BMC Obes 6, 3.

7. Elkum N, Al-Arouj M, Sharifi M, et al. (2016) Prevalence of childhood obesity in the state of Kuwait. Pediatr Obes 11, e30-e34.

8. AlMarri F, Al Sabah S, Al Haddad E, et al. (2017) A call for more research from the Arabian Gulf. Obes Surg 27, 2034-2043.

9. Alghais N, Pullar D, \& Charles-Edwards E (2018) Accounting for peoples' preferences in establishing new cities: a spatial model of population migration in Kuwait. PLOS ONE 13, e0209065.

10. Al-Sabah SK, Almazeedi SM, Dashti SA, et al. (2015) The efficacy of laparoscopic sleeve gastrectomy in treating adolescent obesity. Obes Surg 25, 50-54.

11. Friedemann C, Heneghan C, Mahtani K, et al. (2012) Cardiovascular disease risk in healthy children and its association with body mass index. BMJ 345, e4759.

12. Reilly JJ, Kelnar CJ, Alexander DW, et al. (2003) Health consequences of obesity. Arch Dis Child 88, 748-752.

13. Reilly JJ \& Kelly J (2011) Long-term impact of childhood obesity on adult morbidity and premature mortality: systematic review. Int J Obes 35, 891-898.

14. Booth JN, Tomporowski PD, Boyle JM, et al. (2014) Obesity impairs academic attainment in adolescence: findings from ALSPAC, a UK cohort. Int J Obes 38, 1335-1342.

15. Santana CCA, Hill JO, Azevedo LB, et al. (2017) The association between obesity and academic performance in youth: a systematic review. Obesity 18, 1191-1199.

16. Hill AJ, Rodriguez Lopez R, \& Caterson ID (2019) The relationship between obesity and tertiary education outcomes: a systematic review. Int J Obes 43, 2125-2133.

17. Martin A, Booth JN, Laird Y, et al. (2018) Physical activity, diet and other behavioural interventions for improving cognition and school achievement in children and adolescents with obesity or overweight. Cocbrane Database Syst Rev 1, Cd009728.

18. Reilly SM \& Saltiel AR (2017) Adapting to obesity with adipose tissue inflammation. Nat Rev Endocrinol 13, 633-643.

19. Ellulu MS, Patimah I, Khaza'ai H, et al. (2017) Obesity and inflammation: the linking mechanism and the complications. Arch Med Sci 13, 851-863.

20. Martin A, Booth JN, McGeown S, et al. (2017) Longitudinal associations between childhood obesity and academic achievement: systematic review with focus group data. Curr Obes Rep 6, 297-313.

21. Al-Hammadi H \& Reilly JJ (2020) Classification accuracy of body mass index for excessive body fatness in Kuwaiti adolescent girls and young adult women. Diabet Obes Met Syndr Targets Ther 13, 1043-1049.

22. World Health Organization (2017) Childhood Overweight and Obesity. https://www.who.int/dietphysicalactivity/childhood/en/ (accessed 29 September 2019)

23. Cole TJ, Bellizzi MC, Flegal KM, et al. (2000) Establishing a standard definition for child overweight and obesity worldwide: international survey. BMJ 320, 1240-47. 
24. Esteban-Cornejo I, Cadenas-Sanchez C, Contreras-Rodriguez O, et al. (2017) A whole brain volumetric approach in overweight/ obese children: examining the association with different physical fitness components and academic performance. The ActiveBrains project. NeuroImage 159, 346-354.

25. Esteban-Cornejo I, Mora-Gonzalez J, Cadenas-Sanchez C, et al. (2019) Fitness, cortical thickness and surface area in overweight/ obese children: the mediating role of body composition and relationship with intelligence. NeuroImage 186, 771-781.

26. Cornejo E, Reilly JJ, Ortega FB, et al. (2020) Pediatric obesity and brain functioning: the role of physical activity — a novel and important expert opinion of the European Childhood Obesity Group. Pediatr Obes, (In press). Avilable at www.onlinelibrary.wiley.com/ doi/abs/10.1111/ijpo12649.
27. An R, Yan H, Shi X, et al. (2017) Childhood obesity and school absenteeism: a systematic review and meta-analysis. Obesity Rev 18, $1412-1424$

28. WHO (2010) Country Profile for Environmental Burden of Disease, Kuwait 2009. https://www.who.int/quantifying_ehimpacts/national/countryprofile/kuwait.pdf, accessed June 27, 2020.

29. UNICEF (2014) At a Glance: Kuwait. https://www.unicef.org/infobycountry/kuwait_statistics.html\#119, accessed June 27, 2020.

30. Rey-Lopez JP, Hashem R, Hamer M, et al. (2019) Prevalence of overweight and obesity and associations with socioeconomic indicators: the study of health and activity among adolescents in Kuwait. Minerva Pediatr 71, 326-332.

31. Boodai SA \& Reilly JJ (2013) Health related quality of life of obese adolescents in Kuwait. BMC Pediatr 13, 105. 